\title{
Is cardiac autonomic modulation during upper limb isometric contraction and Valsalva maneuver impaired in COPD patients?
}

This article was published in the following Dove Press journal:

International Journal of COPD

13 March 2017

Number of times this article has been viewed

\author{
Cássia da Luz Goulart ${ }^{1}$ \\ Ramona Cabiddu² \\ Paloma de Borba \\ Schneiders' \\ Elisabete Antunes San \\ Martin' \\ Renata Trimer ${ }^{3}$ \\ Audrey Borghi-Silva ${ }^{2}$ \\ Andréa Lúcia Gonçalves \\ da Silva ${ }^{4,5}$ \\ 'Course of Physiotherapy, University \\ of Santa Cruz do Sul, Rio Grande \\ do Sul, Brazil; ${ }^{2}$ Cardiopulmonary \\ Physiotherapy Laboratory, Nucleus of \\ Research in Physical Exercise, Federal \\ University of São Carlos, São Carlos, \\ Brazil; ${ }^{3}$ Department of Physiotherapy, \\ Federal University of Amazonas, \\ Manaus, AM, Brazil; ${ }^{4}$ Course of \\ Physiotherapy, Department of Health \\ and Physical Education, University of \\ Santa Cruz do Sul, Rio Grande do \\ Sul, Brazil; ${ }^{5}$ Pulmonary Rehabilitation \\ Program, Santa Cruz Hospital, Santa \\ Cruz do Sul, Rio Grande do Sul, Brazil
}

Correspondence: Andréa Lúcia Gonçalves da Silva

Rua Vereador Benno Kist, I780/I5, Bairro Santo Inácio, Santa Cruz do Sul, RS, CEP 96820-688, Brazil Tel +55 5I $37 / 77374$ Email andreag@unisc.br
Purpose: To evaluate the heart rate variability (HRV) indices and heart rate (HR) responses during isometric contraction (IC) and Valsalva maneuver (VM) in COPD patients.

Methods: Twenty-two stable moderate to severe COPD patients were evaluated. R-R intervals were recorded (monitor Polar ${ }^{\circledR}$ S810i) during dominant upper limb IC (2 minutes). Stable signals were analyzed by Kubios HRV ${ }^{\circledR}$ software. Indices of HRV were computed in the time domain (mean HR; square root of the mean squared differences of successive RR intervals [RMSSD] and HRV triangular index [RR tri index]) and in the frequency domain (high frequency [HF]; low frequency $[\mathrm{LF}]$ and $\mathrm{LF} / \mathrm{HF}$ ratio). The HR responses were evaluated at rest, at the peak and at the nadir of the VM (15 seconds). The Valsalva index was also calculated.

Results: During IC: time domain indices (mean HR increased [ $P=0.001]$, RMSSD, and RR tri index decreased $[P=0.005$ and $P=0.005$, respectively]); frequency domain indices (LF increased $[P=0.033]$ and HF decreased $[P=0.002])$; associations were found between forced expiratory volume in 1 second $\left(\mathrm{FEV}_{1}\right)$ vs $\operatorname{RMSSD}(P=0.04 ; r=-0.55), \mathrm{FEV}_{1}$ vs $\mathrm{HR}(P=0.04 ; r=-0.48)$, forced vital capacity (FVC) vs RMSSD $(P=0.05 ; r=-0.62)$, maximum inspiratory pressure (MIP) vs HF ( $P=0.02 ; r=0.68)$. $\mathrm{FEV}_{1}$ and FVC justified $30 \%$ of mean HR. During VM: HR increased $(P=0.01)$; the nadir showed normal bradycardic response; the Valsalva index was $=0.7$.

Conclusion: COPD patients responded properly to the upper limb IC and to the VM; however, HR recovery during VM was impaired in these patients. The severity of the disease and MIP were associated with increased parasympathetic modulation and higher chronotropic response.

Keywords: heart rate, autonomic nervous system, COPD, isometric contraction, Valsalva maneuver

\section{Introduction}

COPD is characterized by progressive airflow limitation and is associated with abnormal inflammatory response of the airways and lungs, caused by inhalation of noxious gases and particles, such as those contained in tobacco smoke. ${ }^{1}$ Besides inducing lung damage, COPD presents multisystemic manifestations and can be associated with comorbidities which greatly affect prognosis. ${ }^{1}$ The association between these factors can determine structural and functional changes in the respiratory and peripheral skeletal muscles which directly affect cardiac autonomic modulation, possibly increasing risk of mortality in these patients. ${ }^{2,3}$

The cardiovascular system functioning and the mechanisms regulating the autonomic adjustments have been investigated, both in basal and physical effort conditions by the analysis of heart rate variability (HRV), ${ }^{3}$ which represents a powerful research tool capable of identifying increased risk of mortality ${ }^{4-8}$ and poor prognosis 8 in these patients. 
COPD patients present attenuated response of the HRV index and previous studies have shown increased sympathetic activity, during lower limb aerobic and resistance exercise. ${ }^{2,9-11}$ In addition, these HRV attenuated responses seem to be related to respiratory muscle weakness. ${ }^{12}$ Other studies, however, showed that impaired responses during exercise in these patients may be partially explained by bronchoconstriction, hypoxemia, hypercapnia, and systemic inflammation. ${ }^{9,13-16}$

Isometric contraction (IC) and the Valsalva maneuver (VM) are widely used autonomic tests to assess altered autonomic responses in different populations. ${ }^{11,17}$ Physiologically, IC causes a marked increase in systolic blood pressure (SBP) and heart rate (HR), due to inhibition of vagal modulation on the sinus node, ${ }^{11,17}$ which is dependent on the percentage of maximum voluntary contraction. As for the VM, it determines marked hemodynamic changes, with accentuated cardiovascular overload. ${ }^{18,19}$ However, the studies which investigated the cardiac autonomic responses to these maneuvers in COPD patients are scarce. Stewart et $\mathrm{al}^{20}$ observed the HR responses to the handgrip test and the VM and they concluded that $18 \%$ of COPD patients had attenuated autonomic responses consistent with autonomic neuropathy and these were associated with hypoxemia. ${ }^{20}$ However, in their study, the patients' cardiac autonomic function was not evaluated by means of HRV analysis. ${ }^{20}$ It is noteworthy that such maneuvers provide indices which represent powerful predictors of cardiovascular impairment and reliable diagnostic and prognostic markers. ${ }^{21-23}$

Therefore, the aim of the present study was to evaluate the HRV indices and HR responses during IC and VM in COPD patients. We hypothesized that the severity of COPD would negatively impact on the autonomic responses during IC and VM.

\section{Methods}

\section{Study design}

We performed a cross-sectional and randomized cross-over study within Santa Cruz Hospital's Pulmonary Rehabilitation Program (Santa Cruz do Sul, RS, Brazil). All patients were formally invited to participate in the study by the responsible researcher. The study was approved by the Research Ethics Committee of the University of Santa Cruz do Sul, protocol number 128943, and all volunteers signed an informed consent statement prior to participation.

\section{Subjects}

After acceptance of the patients, 30 patients with a clinical diagnosis of COPD from a physician; forced expiratory volume in 1 second $\left(\mathrm{FEV}_{1}\right)$ /forced vital capacity (FVC) ratio $<0.7$ and $\mathrm{FEV}_{1}<60 \%$ of predicted, with good cognitive function and without disease exacerbation during the previous 15 days were included in the study. Patients with musculoskeletal disorders or neurological conditions affecting the locomotor system in such a way that would preclude participation in the protocol, a clinical diagnosis of lung cancer, current alcoholism, complex cardiac arrhythmias, uncontrolled metabolic disease such as diabetes, thyroid changes and systemic arterial hypertension (with or without the use of beta-blockers) or electrocardiogram alterations were excluded from the study $(n=8)$ (Figure 1).

\section{Measurements}

Patients were evaluated in a laboratory at a temperature of $22^{\circ} \mathrm{C}$ and relative humidity between $50 \%$ and $60 \%$. They were instructed to avoid stimulants and alcoholic drinks and not to perform exhausting physical exercise the day before the test; they were also instructed not to smoke or use bronchodilators for 6 hours before the test. Patients underwent a clinical evaluation to record: sex, age, body mass index, smoking history and COPD staging. Afterward, vital signs (SBP, diastolic blood pressure [DBP], respiratory frequency $[\mathrm{RF}]$, peripheral oxygen saturation $\left[\mathrm{SpO}_{2}\right]$ ) were measured and the dominant upper limb perceived exertion was estimated using the Borg scale.

In addition, familiarization procedures were performed with the equipment and experimental protocols so that patients could learn how to correctly perform the dominant upper limb IC and the VM before the actual testing. The HRV signal was recorded at rest (5 minutes), during upper limb IC ( 2 minutes) and during the VM (15 seconds), the order of which was determined by simple randomization by envelope, and during recovery (5 minutes) (Figure 1).

\section{Pulmonary function}

The pulmonary function was assessed using a digital spirometer (Microloop ${ }^{\circledR}$, MK8, Care Fusion, Hoechberg, Germany), which provided measures of the FVC, the $\mathrm{FEV}_{1}$, and the $\mathrm{FEV}_{1} / \mathrm{FVC}$ ratio. Spirometry was performed according to the recommendations of the American Thoracic Society ${ }^{24}$ and the results were analyzed according to the values predicted by Pereira et al. ${ }^{25}$ The classification of severity of airflow limitation in COPD was performed according to the Global Initiative for Chronic Obstructive Lung Disease (GOLD) recommendations and patients were classified as moderate (GOLD II), severe (GOLD III), or very severe (GOLD IV). ${ }^{1}$ 


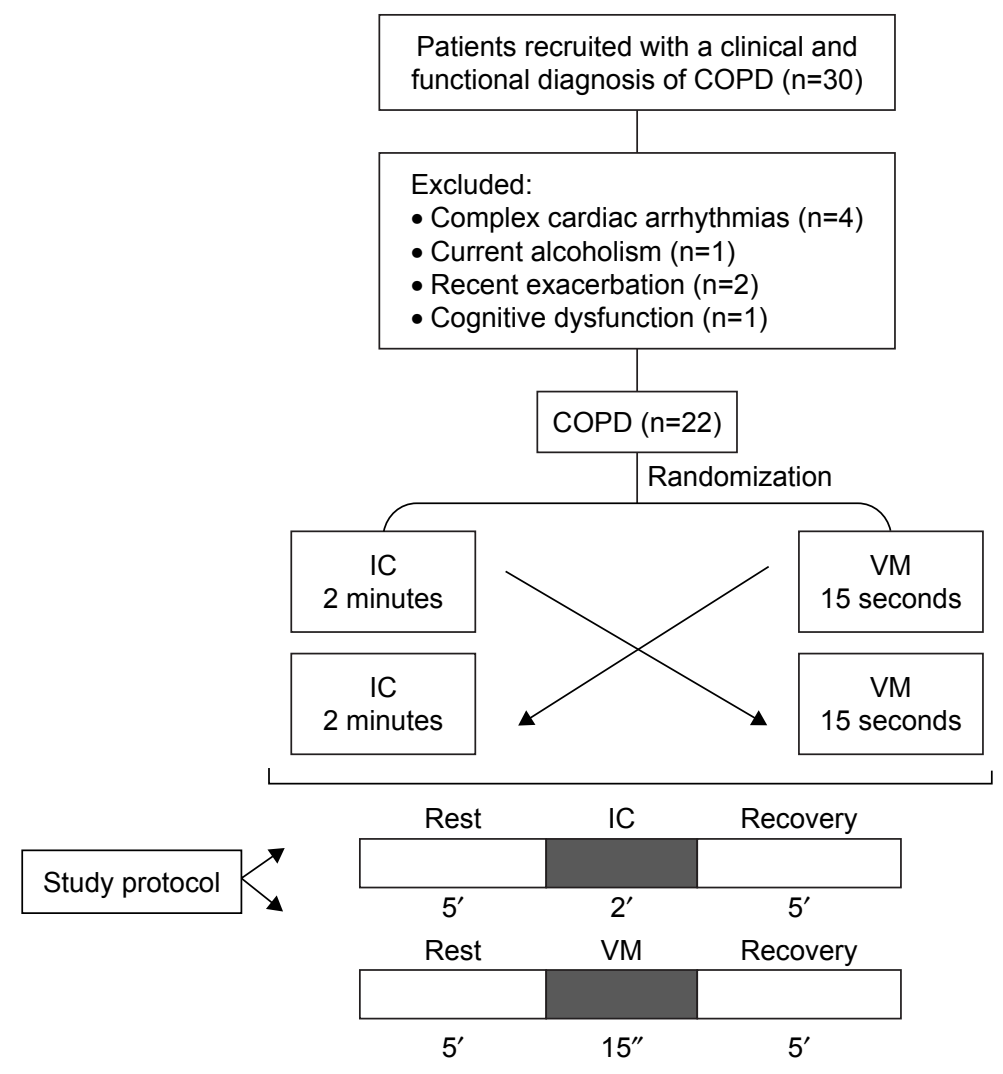

Figure I Flowchart - sampling and study phases.

Notes: 5': 5 minutes; 2': 2 minutes; 15": 15 seconds.

Abbreviations: $\mathrm{n}$, number of patients; IC, isometric contraction; VM, Valsalva maneuver.

\section{Respiratory muscle strength (RMS)}

The RMS was assessed using a digital manometer (MDI ${ }^{\circledR}$, MVD300, Porto Alegre, Brazil), which provided measures of the maximum inspiratory pressure (MIP) and the maximum expiratory pressure (MEP). The assessment was performed according to the recommendations for the Brazilian population. MIP and MEP were obtained from residual volume and total lung capacity; during the maneuver, the subjects remained seated, wearing nose clips and with a rigid, plastic flanged mouthpiece in place. ${ }^{26}$ The values were then compared with those described in literature and expressed as percentage of predicted values. ${ }^{26}$ The inspiratory muscle weakness was determined by an MIP $<60 \mathrm{cmH}_{2} \mathrm{O}^{27}$

\section{Hand-grip strength (HGS) and IC load determination}

The HGS was determined during dominant upper limb IC, using a hand dynamometer ( Jamar $^{\circledR}$, Bolingbrook, IL, USA); three maximum contractions were performed and their average was computed. ${ }^{28}$ The IC load was determined as $30 \%$ of the HGS. The load should be sustained for 2 minutes, preceded by 5 minutes of rest and followed by 5 minutes of recovery. Patients performed dominant upper limb IC while sitting, with shoulder abducted, elbow flexed to $90^{\circ}$, forearm in neutral pronation-supination and wrist extended between $0^{\circ}$ and $30^{\circ} .{ }^{29}$

\section{VM}

The VM was performed with patients in sitting position. After a deep inspiration their nose was occluded by a nose clip to prevent air leakage. The patients performed a breathholding maneuver for 15 seconds, ${ }^{30}$ after which expiration was initiated on the researcher's command. Facial flushing, jugular stasis, chest movements and rapid HR increase followed by bradycardia were observed to guarantee the correct performance of the VM. ${ }^{30}$ The test was preceded by 5 minutes of rest and followed by 5 minutes of recovery.

\section{HRV}

HR and RR intervals (iR-R) were recorded using a telemetric cardiac monitor (Polar ${ }^{\circledR}$ S810i, Kempele, Finland). An elastic band (Polar T31 transmitter) was placed around the patient's thorax at the level of the lower third of the sternum, while the patient was in a sitting position; signals 
were continuously transmitted to the receiving unit by electromagnetic field. Recorded data were then transferred to Kubios HRV ${ }^{\circledR}$ analysis software (version 2.2, Finland) for subsequent analysis.

The signal processing was carried out as follows: at rest ( 5 minutes), during upper limb IC (90 seconds; the first 30 seconds of the signal were discarded in order to obtain a stable signal portion), and post-exercise recovery ( 5 minutes). The HRV signal collected during upper limb IC was analyzed in the time domain (the analysis provided mean RR interval [mean RR], RR interval standard deviation [STD RR], mean HR, STD HR, square root of the mean squared differences of successive RR intervals [RMSSD] and the HRV triangular index [RR tri index]) and in the frequency domain (the analysis provided the HRV signal power in the low frequency [LF], indicating sympathetic activity, in the high frequency [HF], indicating parasympathetic activity, and the LF/HF ratio).

As for the VM, the iR-R were analyzed during rest, at the peak of the VM, after cessation of the VM (when the lowest HR value is referred to as nadir), and during recovery. The Valsalva index (VI) was calculated as the ratio between the longest iR-R during recovery and the shortest iR-R during the peak of the VM. The VI is used as an indirect measure of the autonomic nervous system (ANS) integrity, characterized by values above $1.4 .^{31}$

\section{Statistical analysis}

Sample size calculation was performed a priori using Gpower software according to the variable RMSSD; to achieve a statistical power of $80 \%(\beta=0.20)$, with $\alpha=0.05$, it was calculated that a minimum of 20 patients were needed. ${ }^{11}$ Data were analyzed using the Sigmaplot ${ }^{\circledR}$ statistical package (version 11.0, Systat Software Inc., San Jose, CA, USA). Data were tested for normality through the Shapiro-Wilk test and presented descriptively as mean and STD (parametric) or as median and minimum and maximum interval (non-parametric). An analysis of variance (ANOVA) analysis for multiple comparisons with Tukey's post hoc test was performed. A Pearson correlation analysis was performed to investigate the correlations between variables. A linear regression model was used to determine the effect of the clinical variables on the HRV parameters. Residuals were evaluated under the assumptions of normality, constant variance, and independence. $P<0.05$ was considered significant.

\section{Results}

Clinical characteristics of the patients included in the study are shown in Table 1. We observed a prevalence of patients
Table I COPD patients' clinical characteristics

\begin{tabular}{|c|c|}
\hline Variables & COPD $(n=22)$ \\
\hline Age (years) & $63.5 \pm 7.3$ \\
\hline Sex, male, n (\%) & $15(68.2)$ \\
\hline BMI $\left(\mathrm{kg} / \mathrm{m}^{2}\right)$ & $26.0 \pm 5.2$ \\
\hline \multicolumn{2}{|l|}{ BMI classification } \\
\hline Underweight, n (\%) & $5(22.7)$ \\
\hline Eutrophic, n (\%) & $7(3 \mid .8)$ \\
\hline Obese, n (\%) & $10(45.5)$ \\
\hline \multicolumn{2}{|l|}{ Pulmonary volumes } \\
\hline $\mathrm{FEV}_{1}(\mathrm{~L} / \mathrm{s})$ & I.0 \pm 0.6 \\
\hline FEV, (\% predicted) & $38.0 \pm 19.5$ \\
\hline FVC (L/s) & $1.9 \pm 0.5$ \\
\hline FVC (\% predicted) & $56.2 \pm 16.5$ \\
\hline $\mathrm{FEV}_{1} / \mathrm{FVC}$ & $0.5 \pm 0.1$ \\
\hline FEV /FVC (\% predicted) & $65.3 \pm 21.3$ \\
\hline \multicolumn{2}{|l|}{ Staging (GOLD) } \\
\hline Stage II, n (\%) & $5(22.7)$ \\
\hline Stage III, n (\%) & $10(45.5)$ \\
\hline Stage IV, n (\%) & $7(3 \mid .8)$ \\
\hline \multicolumn{2}{|l|}{ Respiratory muscle strength } \\
\hline $\mathrm{MIP}\left(\mathrm{cmH}_{2} \mathrm{O}\right)$ & $-68.0 \pm 29.9$ \\
\hline MIP (\% predicted) & $72.9 \pm 33.9$ \\
\hline $\operatorname{MEP}\left(\mathrm{cmH}_{2} \mathrm{O}\right)$ & $99.2 \pm 38.3$ \\
\hline MEP (\% predicted) & $98.6 \pm 33.3$ \\
\hline \multicolumn{2}{|l|}{ Hand-grip strength } \\
\hline Dominant (kgf) & $30.3 \pm 11.1$ \\
\hline $30 \%$ (sustained) & $9.0 \pm 3.4$ \\
\hline \multicolumn{2}{|l|}{ MIP $<60 \mathrm{cmH}_{2} \mathrm{O}, \mathrm{n}(\%)$} \\
\hline Yes & II (50.0) \\
\hline No & II (50.0) \\
\hline
\end{tabular}

Note: Data presented as mean \pm standard deviation unless stated otherwise. Abbreviations: $\mathrm{n}(\%)$, number of patients (\% of sample size); BMI, body mass index; $\mathrm{FEV}_{\text {, }}$, forced expiratory volume in I second; FVC, forced vital capacity; GOLD, Global Initiative for Chronic Obstructive Lung Disease; MIP, maximum inspiratory pressure; MEP, maximum expiratory pressure.

of male sex, with obesity, and with severe COPD in stage III and IV (77\%). Despite the higher frequency of patients with severe disease, the changes in inspiratory muscle strength were also distributed among the patients studied (50\% MIP normal values and 50\% inspiratory muscle weakness).

Table 2 shows that the upper limb IC significantly increased the SBP $(P=0.002)$, the DBP $(P=0.020)$, the RF $(P=0.007)$, and the upper limb perceived exertion $(P<0.001)$; as for the time domain index, mean HR increased $(P=0.001)$, while RMSSD and RR tri index decreased $(P=0.005$ and $P=0.005$, respectively), suggesting an HR increase and a vagal activity and total HRV decrease. As for the frequency domain index, the LF power increased $(P=0.033)$ and the HF power decreased $(P=0.002)$, indicating a sympathetic modulation increase and a vagal modulation decrease.

Moderate to strong correlations were found between inspiratory muscle strength, airway obstruction and lung 
Table 2 Clinical and HRV parameters at rest, during IC and during recovery

\begin{tabular}{|c|c|c|c|}
\hline \multirow[t]{2}{*}{ Variables } & \multicolumn{3}{|l|}{ COPD $n=22$} \\
\hline & Rest & IC & Recovery \\
\hline SBP $(\mathrm{mmHg})$ & $109.5 \pm 11.8$ & $124.0 \pm 15.8^{*}$ & $117.6 \pm 10.4$ \\
\hline $\mathrm{DBP}(\mathrm{mmHg})$ & $70.2 \pm 7.7$ & $73.9 \pm 7.1 *$ & $67.8 \pm 6.7^{\alpha}$ \\
\hline $\mathrm{RF}$ (rpm) & $18.6 \pm 2.9$ & $21.6 \pm 2.9 *$ & $19.8 \pm 3.0$ \\
\hline $\begin{array}{l}\text { BORG - upper } \\
\text { limb }\end{array}$ & $6.0(6.0-6.0)$ & | $3.0(9.2-\mid 4.0)^{*}$ & $8.0(6.2-9.0)^{\alpha, \#}$ \\
\hline $\mathrm{SpO}_{2}(\%)$ & $93.1 \pm 2.2$ & $93.4 \pm 1.7$ & $94.0 \pm 1.9$ \\
\hline Mean RR (ms) & $720.9 \pm 120.5$ & $717.5 \pm 87.2$ & $715.4 \pm 86.7$ \\
\hline STD RR (ms) & $17.6 \pm 9.0$ & $12.8 \pm 7.4$ & $18.4 \pm 7.3$ \\
\hline Mean HR (I/min) & $79.4 \pm 13.4$ & $86.9 \pm 12.0^{*}$ & $80.1 \pm 13.9$ \\
\hline STD HR (I/min) & $2.0(1.7-2.3)$ & $1.5(1.0-1.9)^{*}$ & $2.2(1.5-2.9)$ \\
\hline RMSSD (ms) & $17.0(10.0-29.9)$ & $12.4(9.2-15.7)^{*}$ & $17.6(11.3-22.0)^{\alpha}$ \\
\hline RR tri index & $4.4(2.8-6.2)$ & $3.7(2.2-4.5)^{*}$ & $4.8(3.3-6.5)^{\alpha}$ \\
\hline $\mathrm{HF}(\mathrm{nu})$ & $41.7 \pm 20.5$ & $35.5 \pm 14.8^{*}$ & $45.3 \pm 23.3^{\alpha}$ \\
\hline LF (nu) & $53.3 \pm 21.8$ & $61.0 \pm 19.6^{*}$ & $48.3 \pm 23.2^{\alpha}$ \\
\hline LF/HF & I.3 (0.6-4.2) & $\mathrm{I} .4(\mathrm{I} . \mathrm{I}-2.7)^{*}$ & $0.9(0.2-1.4)^{\alpha}$ \\
\hline
\end{tabular}

Notes: Data are presented as mean \pm standard deviation or as median and interquartile range. ANOVA with Tukey's post hoc analysis was performed: $*(P<0.05)$ for IC vs rest; ${ }^{\alpha}(P<0.05)$ for recovery vs IC; ${ }^{*}(P<0.05)$ for recovery vs rest.

Abbreviations: $\mathrm{HRV}$, heart rate variability; IC, isometric contraction; SBP, systolic blood pressure; DBP, diastolic blood pressure; RF, respiratory frequency; $\mathrm{SpO}_{2}$, peripheral oxygen saturation; mean RR, mean RR interval; STD RR, RR interval standard deviation; mean HR, mean heart rate; STD HR, heart rate standard deviation; RMSSD, square root of the mean squared differences of successive RR intervals; RR tri index, HRV triangular index; LF, low frequency; HF, high frequency; nu, normalized units; LF/HF, ratio between LF power and HF power; ANOVA, analysis of variance.

capacity, and the HRV parameters during upper limb IC (Figure 2), demonstrating the influence and importance of airflow obstruction and inspiratory muscle weakness over the parasympathetic modulation and HR behavior.

We could observe that the lung function indices $\left(\mathrm{FEV}_{1}\right.$ and FVC) directly influenced cardiac autonomic modulation during upper limb IC. This result was confirmed by a multiple linear regression, which showed that airway obstruction and lung capacity justified $30 \%$ of mean HR during upper limb IC (Table 3).

The HR behavior during the VM is shown in Figure 3. The HR behavior at rest, during and at the peak of the VM, after cessation of the VM (nadir) and during recovery indicates that the COPD patients included in this study presented an HR response pattern similar to that observed in previous, similar studies performed on other populations. ${ }^{19,30}$ The VI value $(=0.7)$ indicates an integrity loss of the ANS in these patients.

The HR values during the VM are represented in Figure 4. We could observe a significant HR increase during the $\mathrm{VM}$, with a recovery to baseline values after cessation of the maneuver. The nadir suggests an adequate bradycardic response to the maneuver.

The correlations between $\mathrm{FEV}_{1} / \mathrm{FVC}$ with rest-HR and VM-HR underscored the direct influence of airway obstruction on cardiac performance in COPD patients (Figure 5).

\section{Discussion}

The main findings of the present study can be summarized as follows: 1) COPD patients responded properly to the upper limb IC and to the VM; however, 2) HR recovery from the VM appeared to be impaired; 3) the severity of the disease, quantified by $\mathrm{FEV}_{1}$ and FVC, as well as MIP, were associated with increased parasympathetic modulation; 4) chronotropic responses were associated with bronchoconstriction.

As expected, during upper limb IC, patients presented increased HR, increased sympathetic activation and reduced total HRV; we observed that all indices went back to their normal values during recovery. A previous study showed that $18 \%$ of COPD patients presented attenuated autonomic responses, consistent with autonomic neuropathy and associated with hypoxemia. ${ }^{20}$ However, in that study, the authors did not evaluate cardiac autonomic modulation by computing robust HRV indices, but only by analyzing HR responses, ${ }^{20}$ different to our study, in which linear and nonlinear HRV indices, widely accepted as important tools to determine cardiac autonomic changes, were studied. ${ }^{32,33}$

We observed an association between airway obstruction and inspiratory muscle weakness (Figure 2). These findings were previously reported by other authors in different autonomic tests, as postural change, and during dynamic exercise. ${ }^{2,3,12,13}$ It has been reported that increased cardiac parasympathetic modulation in COPD patients was directly associated with increased airway obstruction. ${ }^{15}$ This response may be associated with changes in both lung compliance and lung stretch reflex responses in patients with cardiopulmonary disease. ${ }^{13}$

A particularly relevant finding of our study is the association between HR chronotropic response during IC and the severity of the disease. These results may be explained by augmented muscle metaboreflex activation that could occur in those patients at a more severe stage of COPD. ${ }^{22}$ This mechanism, associated with systemic inflammation present in COPD, may contribute to augmented sympathetic responses to exercise. ${ }^{16}$ Our results confirm the importance of applying the IC maneuver, which has been widely used for risk assessment in cardiovascular disease patients, as a powerful tool to assess the severity of the disease in this population. ${ }^{22}$ 

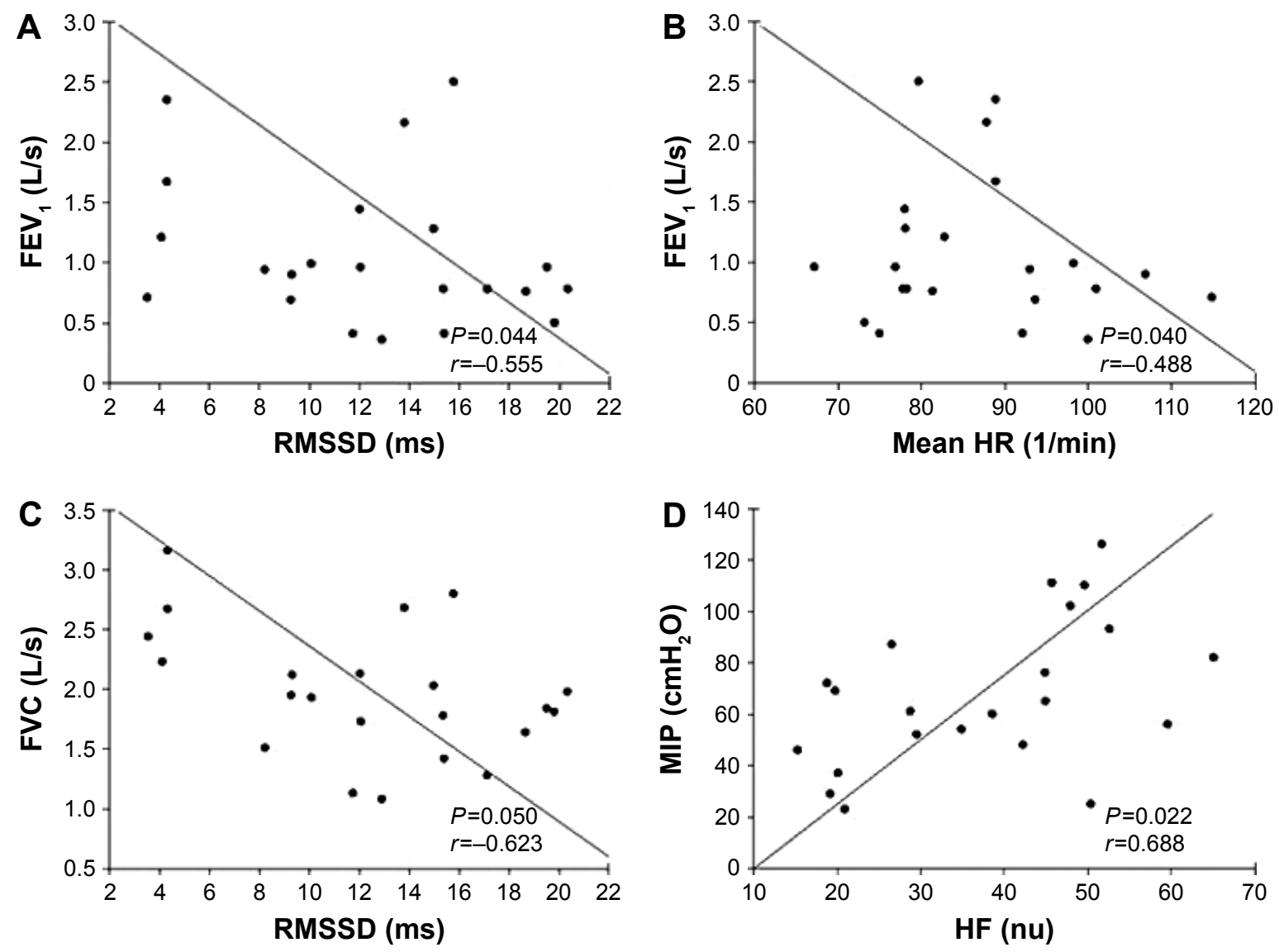

Figure 2 Relationship between respiratory muscle strength and lung function, and heart rate variability index during upper limb isometric contraction. Notes: (A) Negative correlation between RMSSD (ms) and FEV, (L/s); (B) negative correlation between mean HR (I/min) and FEV $(\mathrm{L} / \mathrm{s})$; (C) negative correlation between RMSSD (ms) and FVC (L/s); (D) positive correlation between HF (nu) and MIP ( $\left.\mathrm{cmH}_{2} \mathrm{O}\right)$. The Pearson correlation analysis was performed. Significance level: $P \leq 0.05$.

Abbreviations: RMSSD, square root of the mean squared differences of successive RR intervals; FEV , forced expiratory volume in I second; mean HR, mean heart rate; FVC, forced vital capacity; HF, high frequency; nu, normalized units; MIP, maximum inspiratory pressure; $\mathrm{cmH}_{2} \mathrm{O}$, centimeters of water.

It has been reported that, in cardiac patients and in healthy young people, HR increases at the beginning of the IC, due to increased muscle tension; this phenomenon may be attributed to vagal withdrawal on the sinus node. ${ }^{11,17,34,35}$ The mechanisms responsible for these responses after muscle fiber activation may have a central role in the activation of central neural circuits and in the determination of cardiovascular adjustments. ${ }^{34-36}$ In the present study, we observed expected HR responses in COPD patients.

Table 3 Results of multiple linear regression to determine the influence of FEV, and FVC on mean HR during upper limb isometric contraction

\begin{tabular}{lll}
\hline Variables & $\beta$ coefficient & $P$-value \\
\hline Constant & 64.58 & $<0.001$ \\
FEV & -18.92 & 0.018 \\
FVC & 21.64 & 0.014 \\
\hline
\end{tabular}

Notes: Adjusted $R^{2}=0.298 ; F=3.67(P=0.045)$. Equation to predict mean HR during isometric contraction: $64.58+(21.64 \times \mathrm{FVC})-\left(\right.$ I8.92 $\left.\times \mathrm{FEV}_{1}\right)$.

Abbreviations: $\mathrm{FEV}_{\text {, }}$, forced expiratory volume in I second; mean $\mathrm{HR}$, mean heart rate; FVC, forced vital capacity.
However, the respiratory muscle weakness, suggested by MIP reduction, seems to be associated with cardiac autonomic control impairment. ${ }^{12}$ Moreover, air trapping and subsequent $\mathrm{FEV}_{1}$ reduction, present in severe COPD patients, as well as accentuated bronchoconstriction, have been shown to be associated with vagal tone attenuation and with cardiac autonomic control alteration. ${ }^{12,13}$ Therefore, it could be supposed in our study that impaired RMS and reduced $\mathrm{FEV}_{1}$ and FVC could deeply influence the HRV behavior, both at rest and during isometric exercise.

Interestingly, in our study, during the VM, COPD patients presented an expected HR response; however, the HR values could not be fully recovered 5 minutes after cessation of the maneuver. These aspects are particularly relevant since it is well known that the recovery of the HR response represents a powerful prognostic marker for cardiovascular disease. ${ }^{19}$ The HR response to the VM is mainly influenced by cardiac autonomic control, which is responsible for the rapid increase phase, with vagal withdrawal over the sinus node, as well as for the 

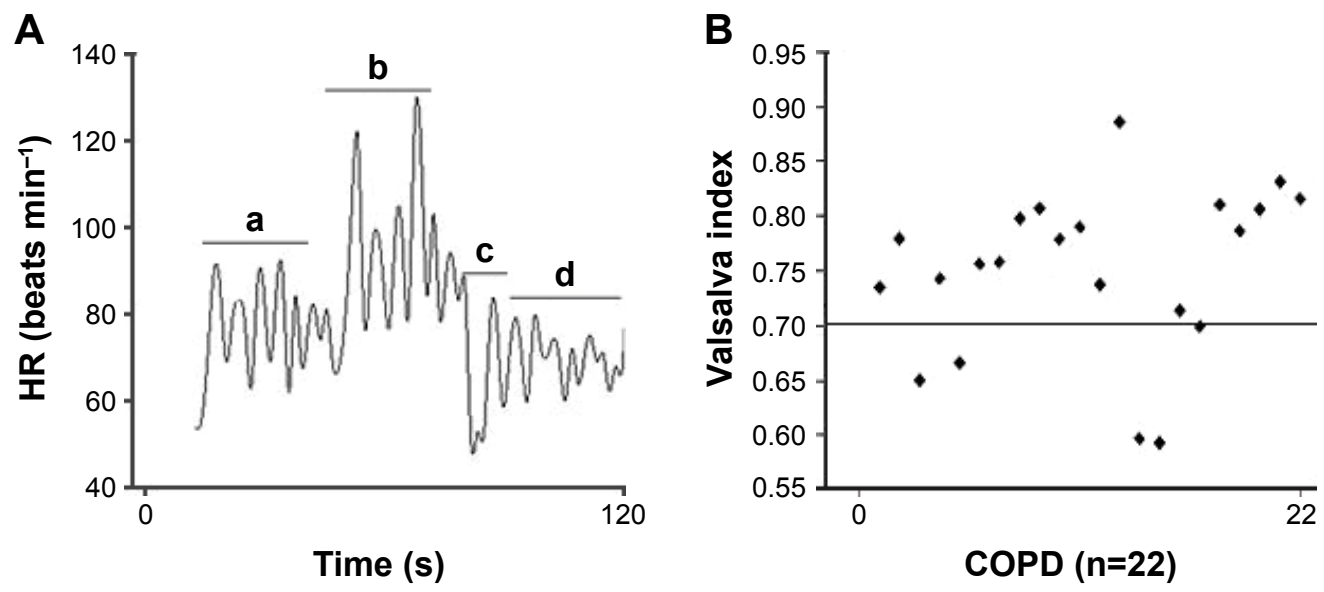

Figure 3 Response of HR during the VM in COPD patients.

Notes: (A) Beat-to-beat HR response during the VM of one patient. a, rest; b, peak of the VM; c, Nadir value and d, recovery. COPD patients presented an expected HR response pattern, with an increase during the VM, followed by bradycardia after cessation of the VM, and with a final increase during recovery. (B) VI of the COPD patients. The mean $\mathrm{VI}$ value $(=0.75 \pm 0.0)$ indicates an ANS integrity loss in these patients.

Abbreviations: ANS, autonomic nervous system; HR, heart rate; VM, Valsalva maneuver; VI, Valsalva index.

reduction after cessation of the VM, with vagal tone activation. These adjustments may occur in response to the activation of cardiopulmonary receptors and arterial baroreceptors. ${ }^{17,19,37,38}$

The present study is relevant as it highlights the direct influence of the airway obstruction on the HR parameters (Figure 5). The interaction between sympathetic reflex and vagal reflex, probably triggered by the pulmonary stretch receptors, is responsible for the cardiovascular responses during the VM. ${ }^{17,19,37}$ The peripheral vascular resistance, which increases in response to decreased venous return, caused by increased intrathoracic pressure during the VM, drops immediately after cessation of the maneuver; this promotes an increase in venous return which, through the baroreceptors, stimulates vagal recovery, leading to

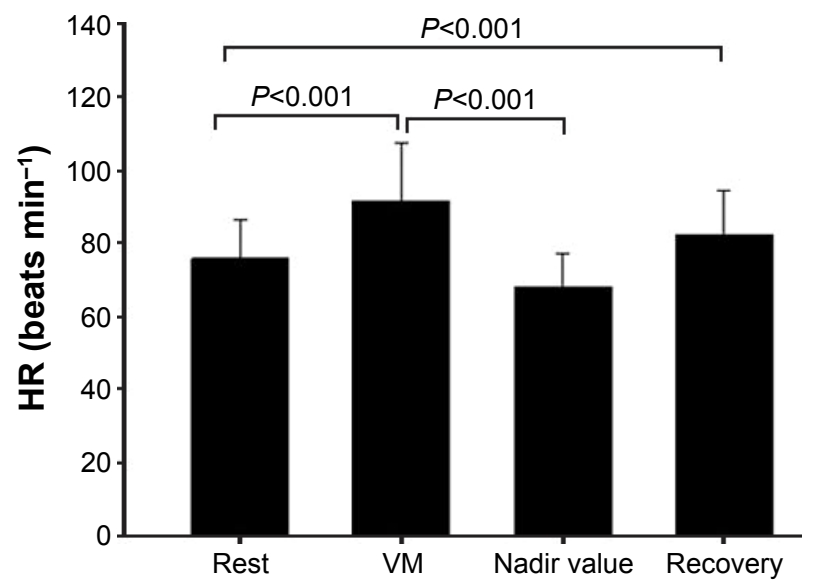

Figure $4 \mathrm{HR}$ values during the VM.

Notes: ANOVA with Tukey's post hoc analysis was performed. Significance level: $P<0.05$.

Abbreviations: HR, heart rate; VM, Valsalva maneuver; ANOVA, analysis of variance. marked bradycardia. ${ }^{30,37}$ Taking into account the structural and mechanical pathophysiological changes in the respiratory system of COPD patients, the results reported in literature justify a VI lower than 0.7 , confirming an ANS integrity loss in these subjects.

This study has limitations that should be addressed. Given our strict exclusion criteria, and the difficulty in triaging patients with a $95 \%$ rate of sinus rhythm, our sample may not be representative for the entire COPD population, as many patients present various types of arrhythmias that compromise the recording and analysis of signals. In accordance with our main objective, we chose to perform a randomized cross-sectional study to minimize inter-individual variability, where the patient represented his or her own control, which justified the absence of a control group.

This study is of great significance for the clinical management of COPD patients; our results about upper limb IC, about the influence of inspiratory muscle weakness and lung function, and about these patients' responses to the VM, can contribute to the development of novel diagnostic tools; moreover, they may be used to develop modern tools for the evaluation, in the clinical setting, of the effects of pulmonary rehabilitation interventions, such as respiratory muscle training and static and dynamic resistance training.

\section{Conclusion}

The COPD patients included in this study responded appropriately to the upper limb IC, with an HR increase, a sympathetic modulation increase, and a parasympathetic modulation decrease. However, the recovery of the HR after the VM was impaired and the VI presented a value 

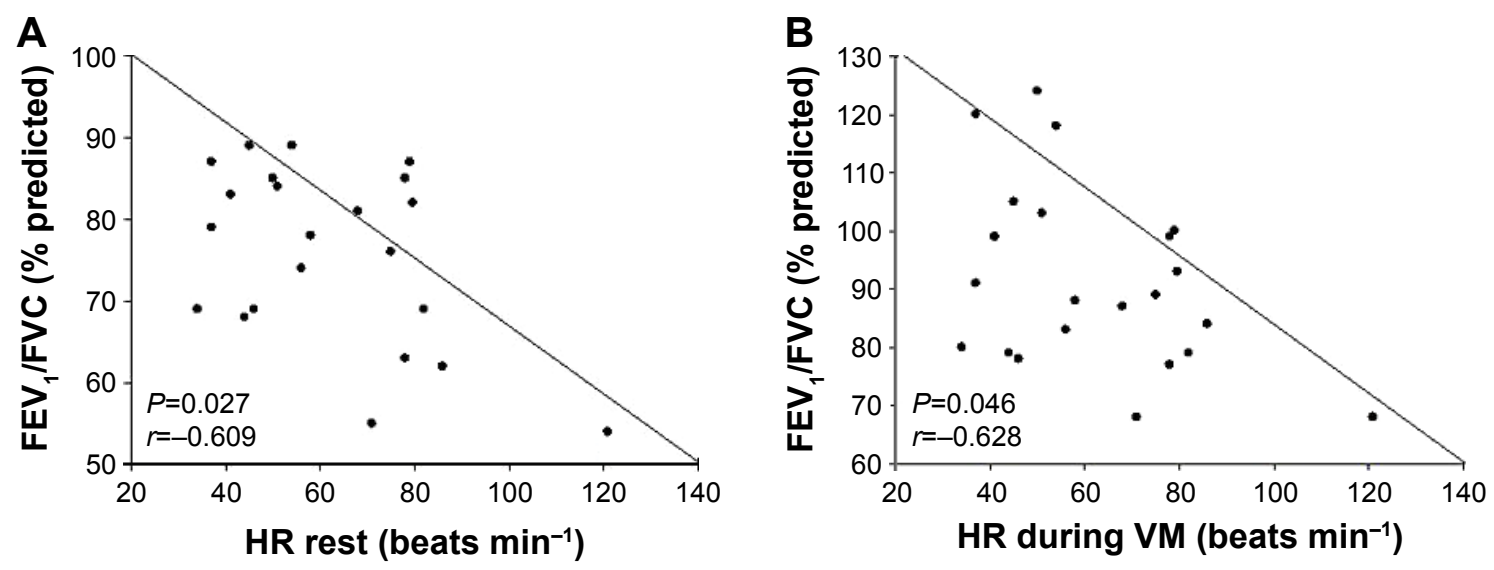

Figure 5 Relationship between lung function and HR values during the VM in COPD patients.

Notes: (A) Negative correlation between FEV, /FVC (\% predicted) and HR; (B) negative correlation between FEV, /FVC (\% predicted) and HR during the VM. Significance level: $P<0.05$. The Pearson correlation analysis was performed.

Abbreviations: HR, heart rate; VM, Valsalva maneuver; FEV , forced expiratory volume in I second; FVC, forced vital capacity.

below normal range. The severity of the disease and MIP were associated with increased parasympathetic modulation. Finally, higher chronotropic response was associated to bronchoconstriction in these patients.

The main findings of the present study can be summarized as follows: COPD patients responded properly to the upper limb IC and to the VM; HR recovery after VM appeared to be impaired; the severity of the disease was associated with increased parasympathetic modulation; chronotropic responses were associated to bronchoconstriction.

\section{Author contributions}

All authors made substantial contributions to conception and design, acquisition of data, or analysis and interpretation of data; took part in drafting the article or revising it critically for important intellectual content; and agree to be accountable for all aspects of the work.

\section{Acknowledgments}

Grants were received from the University of Santa Cruz do Sul - UNISC, Santa Cruz Hospital and DECIT/SCTIE-MS/ FAPERGS/CNPq 1264-2551/13-1; CAPES, project no 88881.062123/2014-01; FAPESP, project no 2013/23013-0.

\section{Disclosure}

The authors report no conflicts of interest in this work.

\section{References}

1. Global Initiative for Chronic Obstructive Lung Disease. Pocket Guide to COPD Diagnosis, Management and Prevention. Global Initiative for Chronic Obstructive Lung Disease; 2016. Available from: http:// www.goldcopd.it/materiale/2016/GOLD_Pocket_2016.pdf. Accessed July 27, 2016.
2. Roque AL, Valenti VE, Massetti T, et al. Chronic obstructive pulmonary disease and heart rate variability: a literature update. Int Arch Med. 2014;7:43.

3. Nicolino J, Ramos D, Leite MR, et al. Analysis of autonomic modulation after an acute session of resistance exercise at different intensities in chronic obstructive pulmonary disease patients. Int J Chron Obstruct Pulmon Dis. 2015;10:223-229.

4. Gunduz H, Talay F, Arinc H, et al. Heart rate variability and heart rate turbulence in patients with chronic obstructive pulmonary disease. Cardiol J. 2009;16(6):553-559.

5. Theofilogiannakos EK, Anogeianaki A, Tsekoura P, et al. Arrhythmogenesis in patients with stable chronic obstructive pulmonary disease. J Cardiovasc Med (Hagerstown). 2008;9(1):89-93.

6. Mohammed J, Meeus M, Derom E, Da Silva H, Calders P. Evidence for autonomic function and its influencing factors in subjects with COPD: a systematic review. Respir Care. 2015;60(12):1841-1851.

7. van Gestel AJ, Kohler M, Clarenbach CF. Sympathetic overactivity and cardiovascular disease in patients with chronic obstructive pulmonary disease (COPD). Discov Med. 2012;14(79):359-368.

8. Stein PK, Nelson P, Rottman JN, et al. Heart rate variability reflects severity of COPD in PiZ alpha1-antitrypsin deficiency. Chest. 1998; 113(2):327-333.

9. Borghi-Silva A, Arena R, Castello V, et al. Aerobic exercise training improves autonomic nervous control in patients with COPD. Respir Med. 2009;103(10):1503-1510.

10. Machado-Vidotti HG, Mendes RG, Simões RP, Castello-Simões V, Catai AM, Borghi-Silva A. Cardiac autonomic responses during upper versus lower limb resistance exercise in healthy elderly men. Braz $J$ Phys Ther. 2014;18(1):9-18.

11. Leite PH, Melo RC, Mello MF, Silva ED, Borghi-Silva A, Catai AM. Heart rate responses during isometric exercises in patients undergoing a phase III cardiac rehabilitation program. Rev Bras Fisioter. 2010;14(5): 383-389.

12. Goulart CL, Simon JC, Schneiders PB, et al. Respiratory muscle strength effect on linear and nonlinear heart rate variability parameters in COPD patients. Int J Chron Obstruct Pulmon Dis. 2016;11: 1671-1677.

13. Mazzuco A, Medeiros WM, Sperling MP, et al. Relationship between linear and nonlinear dynamics of heart rate and impairment of lung function in COPD patients. Int J Chron Obstruct Pulmon Dis. 2015; 10:1651-1661.

14. Chen WL, Chen GY, Kuo CD. Hypoxemia and autonomic nervous dysfunction in patients with chronic obstructive pulmonary disease. Respir Med. 2006;100(9):1547-1553. 
15. Volterrani M, Scalvini S, Mazzuero G, et al. Decreased heart rate variability in patients with chronic obstructive pulmonary disease. Chest. 1994; 106(5):1432-1437.

16. Chhabra SK, Gupta M, Ramaswamy S, Dash DJ, Bansal V, Deepak KK. Cardiac sympathetic dominance and systemic inflammation in COPD. COPD. 2015;12(5):552-559.

17. Freeman JV, Dewey FE, Hadley DM, Myers J, Froelicher VF. Autonomic nervous system interaction with the cardiovascular system during exercise. Prog Cardiovasc Dis. 2006;48(5):342-362.

18. Korner PI, Tonkin AM, Uther JB - Reflex and mechanical circulatory effects of graded Valsalva maneuvre in normal man. J Appl Physiol. 1976;40:434-440.

19. Minatel V, Takahashi AC, Perseguini NM, et al. Maximal expiratory pressure and Valsalva manoeuvre do not produce similar cardiovascular responses in healthy men. Exp Physiol. 2016;101(5):599-611.

20. Stewart AG, Waterhouse JC, Howard P. Cardiovascular autonomic nerve function in patients with hypoxaemic chronic obstructive pulmonary disease. Eur Respir J. 1991;4(10):1207-1214.

21. Hume L, Irving JB, Kitchin AH, Reuben SR. Effects of sustained isometric handgrip on praecordial accelerocardiogram in normal subjects and in patients with heart disease. Br Heart J. 1975;37(8):873-881.

22. Greaney JL, Edwards DG, Fadel PJ, Farquhar WB. Rapid onset pressor and sympathetic responses to static handgrip in older hypertensive adults. J Hum Hypertens. 2015;29(7):402-408.

23. Abramkin DV, Iavelov IS, Gratsianskiü NA. [Comparison of various methods of assessment of heart rate variability including simple cardiovascular reflex tests as predictors of sudden cardiac death after myocardial infarction]. Kardiologiia. 2004;44(9):34-41. Russian.

24. Gibson GJ, Whitelaw W, Siafakas N. Tests of overall respiratory function. ATS/ERS statement on respiratory muscle testing. Am J Respir Crit Care Med. 2002;166(4):518-624.

25. Pereira CA, Sato T, Rodrigues SC. New reference values for forced spirometry in white adults in Brazil. J Bras Pneumol. 2007;33(4): 397-406.

26. Neder JA, Andreoni S, Lerario MC, Nery LE. Reference values for lung function tests. II. Maximal respiratory pressures and voluntary ventilation. Braz J Med Biol Res. 1999;32(6):719-727.

27. Beaumont M, Mialon $\mathrm{P}$, Le Ber-Moy C, et al. Inspiratory muscle training during pulmonary rehabilitation in chronic obstructive pulmonary disease: a randomized trial. Chron Respir Dis. 2015;12(4):305-312.
28. Luna-Heredia E, Martin-Pena G, Ruiz-Galiana J. Handgrip dynamometry in healthy adults. Clin Nutr. 2005;24(2):250-258.

29. Castro CL, Nóbrega AC, Araújo CG. Testes Autonômicos Cardiovasculares. Uma Revisão Crítica. Parte I e II. [Autonomic cardiovascular tests: a critical review. I and II]. Arq Bras Cardiol. 1992;59:75-83. Portuguese.

30. Minatel V, Karsten M, Neves LM, Beltrame T, Borghi-Silva A, Catai AM. Heart rate assessment during maximal static expiratory pressure and Valsalva maneuver in healthy young men. Rev Bras Fisioter. 2012; 16(5):406-413.

31. O'Brien IA, O'Hare P, Corrall RJ. Heart rate variability in healthy subjects: effect of age and the derivation of normal ranges for tests of autonomic function. Br Heart J. 1986;55(4):348-354.

32. No authors listed. Heart rate variability: standards of measurement, physiological interpretation and clinical use. Task Force of the European Society of Cardiology and the North American Society of Pacing and Electrophysiology. Circulation. 1996;93(5):1043-1065.

33. Luczak H, Lauring WJ. An analysis of heart rate variability. Ergonomics. 1973;16(1):85-97.

34. Silva E, Oliveira L, Catai AM, Ferreira Filho P, Bérzin F, Gallo Júnior L. Evaluation of electromyographic activity and heart rate responses to isometric exercise. The role played by muscular mass and type. Braz J Med Biol Res. 1999;32(1):115-120.

35. Stewart JM, Montgomery LD, Glover JL, Medow MS. Changes in regional blood volume and blood flow during static handgrip. Am J Physiol Heart Circ Physiol. 2007;292(1):H215-H223.

36. Williamson JW, Fadel PJ, Mitchell JH. New insights into central cardiovascular control during exercise in humans: a central command update. Exp Physiol. 2006;91(1):51-58.

37. Mitchell JH. J.B. Wolffe memorial lecture. Neural control of the circulation during exercise. Med Sci Sports Exerc. 1990;22(2):141-154.

38. Gallo JR Jr, Maciel BC, Marin-Neto JA, Martins LE, Lima-Filho EC, Manço JC. The use of isometric exercise as a means of evaluating the parasympathetic contribution to the tachycardia induced by dynamic exercise in normal man. Pflugers Arch. 1988;412(1-2):128-132.
International Journal of COPD

\section{Publish your work in this journal}

The International Journal of COPD is an international, peer-reviewed journal of therapeutics and pharmacology focusing on concise rapid reporting of clinical studies and reviews in COPD. Special focus is given to the pathophysiological processes underlying the disease, intervention programs, patient focused education, and self management protocols.

\section{Dovepress}

This journal is indexed on PubMed Central, MedLine and CAS. The manuscript management system is completely online and includes a very quick and fair peer-review system, which is all easy to use. Visit http://www.dovepress.com/testimonials.php to read real quotes from published authors. 